THE JOURNAL OF THE BRITISH MEDICAL ASSOCIATION.

LONDON: SATURDAY, JULY 1sT, 1922.

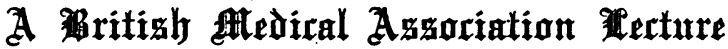 ON THE}

\section{MODERN TREATMENT OF SYPHILIS.} BY

L. W. HARRISON, D.S.O., M.B.GLAS., M.R.C.P.EDIN., DIRECTOR, VENEREAL DISEABES DEPARTMENT, ST. THOMAB'S HOSPITAL,

May I be pardoned for starting my address with the truism that our primary object in treating syphilis, to be kept always before us, is to rid the patient of Spironema pallidum without poisoning him with the remedies employed. Before discussing the present-day treatment I should like to hark back to the days immediately preceding the introduction of "606." I ảo so because I think that some of the lessons we learnt then are apt to be forgotten to-day.

In 1909 we were relying for the treatment of syphilis mainly on mercury and iodides, and many of us found it a task which was full of disappointments. Frequently the patient relapsed whilst actually under treatment; frequently he displayed signs of intolerance in the form of stomatitis or albuminuria whilst showing active signs of syphilis, and no small ingenuity had to be displayed in steering many of our patients to recovery. At that time it was generally considered in this country that two years' treatment sufficed for most cases, though in some other countries four, five, or even more years were regarded as the minimum. Syphilologists in this country were beginning, however, to realize that two years mercurial treatment carried out on lines that are practicable for the multitude was not sufficient for the arerage case, and I was able to show by Wassermann tests on over 400 soldiers, only three months after completion' of two yea's' injection treatment, that over 40 per cent. were positive to the original test and over 70 per cent. to Stern's modification. 'These facts regarding the comparatively feeble effect of marcury and the insufficiency of two jears' treatment by injections of mercury have certainly influenced my own attitude towards the place of mercury in the treatment of syphilis, causing me to con. tinue the use of arsenobenzol remedies far beyond the stage when many workers suspend them.

In 1910 we saw the introduction of arsenobenzol com. pounds, and with it a revolution in antisyphilitic treatment, which is not yet over. The initial effect of " 606 ," which, to us who were accustomed to relying on mercury only, seemed almost magical, accounts for a period during which large numbers of syphilitic patients were undertreated. When we saw lesions which had resisted our most carefuliy planned attacks by mercury disappear in a week or so after a first injection of "606," when we saw that spironemes had dis. appeared completely from the secretions of lesions in twenty. four hours or less, it was hard to resist the temptation to believe that here at last was the long-sought one-dose cure of syphilis. We learnt our error when we saw cases of syphilitic meningitis becoming much more frequent, chiefly in the form of cranial nerve paralyses, and since then we have been increasing gradually the period of treatment until, in many quarters, it has now become the two years of pre-salvarsan days.

At Rochester Row we carried out an investigation to discover the minimum amount of arsenobenzol and mercurial treatment required to cure an average case of early syphifis, and at the outbreak of the war we had arrived at the conclusion that a course consisting of one dose of 0.6 gram "606," five 1-grain doses of mercury, another dose of 0.6 gram "606," five more doses of mercury, and a final dose of 0.6 gram "606," was insufficient treatment, as it had been followed by about 25 per cent. of serological and clinical relapses within a year of suspension of treatment. We had learnt-from other workers' experience, I am glad to saythat if doses of 0.6 gram " 606 " are repeated too frequently, a certain toxic effect of " 606 " was apt to become uncomfortably frequent-namely, epileptiform convulsions, coming on within five days of the injection and often ending fatally. The pathology of this "encephalitis haemorrhagiea" is a widespread thrombosis, or partial thrombosis, of cerebral capillaries, followed by multiple capillary haemorrhages. Some cases show also evidence of similar damage to rena capillaries, and the tubules are found to be packed with red blood cells. You will find in the literature that this is the chief bugbear of the German syphilologists, and is no doubt the reason for the recent edict of the Deutsche Reichsgesund. heilsamt that: $a$. single dose should not exceed 0.4 gram " 606 ."

My task in the war seemed at first only to devise a treat. ment which would enable us to increase on our pre-war treatment in the matter of dosage and yet decrease the length of the course without giving rise to a large percentage of "encephalitis haemorrhagica" and "haemorrhagic ne. phritis." So I split the doses, and at first gave eight doses of 0.3 gram " 606 " in twenty-eight days, with mercury. The event more than justified my hope that we should jargely avoid encephalitis by this plan, because very few cases were recorded in the whole war, but we began to see other toxic effects which $I$ had never witnessed before-namely, der. matitis and jaundice-and it can safely be said that these are the main toxic effects which we have to fear from arsenobenzol treatment to.day. It is true that we have also to reckon with vasomotor disturbances coming on during, or very quickly after, injections, but these, though sometimes alarming, are seldom, if ever, fatal.

Jaundice and dermatitis have certain features in common. Both arc apt to be fatal, and both may appear long after a course of injections has been given-dermatitis as long as three months, and jaundice even twelve months later, though either may commence at any time during the course. It was this incubation period which caused me to introduce intervals of ten to fourteen days into the course of treatment, in tho hope of catching the susceptible cases before too much arsenic had been given, and the course was lengthened first to forty. two days, then to fifty, and lastly to fifty:seven days. The resuit was that, by the end of the war, the incidence of both dermatitis and jaundice had become aimost negligible in the military hospitals in this country. We learnt also that, if every patient is watched carefully during the course of treat. ment, and the injections are stopped on the first signs of an erythema, the incidence of severe dermatitis is very considerably reduced. Sicard has drawn attention to a sign of skin intolerance which I think may prove of some value. This sign is a patch of erythema provolsed by the iodine which is painted on the bend of the elbow before the injection, and visible when the patient is about to be injected again. Sicard also considers that loss of the tendo Achillis jerk during the course of treatment is a sign that the patient is becoming poisoned by the arsenobenzol. Dermatitis has become much less frequent since the war, and I think it is because our patients are under less exposed conditions. I learnt quickly in France that dermatitis is much more severe in winter, and that, as soon as it commences, the patient must be protected, or he will die of pneumonia.

Jaundice, on the other hand, has become more frequent. At first I thought jaundice of no great moment, but two outbreaks in nilitary hospitals in this country in 1917 and early 1918 made me think much more seriously of it. In' one 
hospital fifteen cases died in about nine months of acute yellow atrophy, and in another, three in about three months. The cause of these outbrealss is still rather obscure. They have been noted elsewhere, and have seemed to bear no relation to any change in technique or remedy. At first I thought acute yellow atrophy to $\cdot$ be a liver disturbance of a different order from the liver disturbance we find in ordinary cases of jaundice following arsenobenzol treatment, but the evidence seems to point at present to the two types depending on liver poisoning of different degrees of severity. It is still uncertain whether this jaundice is due entirely to arsenobenzol, or whether there is another factor, either predisposing or precipitating. It seems strange that it should occur in small outbreaks if it is entirely due to arsenobenzol, and, just as in trinitrotoluene poisoning, which it resembles very closely, the theory of an intervening factor is very tempting. There is no doubt, however, that arsenobenzol does cause hepatic inefficiency, as Mackenzie Wallis at St. Bartholomew's Hospital and Spence and Brett at St. Thomas's Hospital have shown by the laevulose blood sugar test, and this inefficiency persists for as long as three months after a course of injections. The resemblance of what I may call arsenobenzol poisoning to that seen in the war amongst workers with T.N.T. has given rise to the idea that it is not due so much to the arsenic as to the organic complex of arsenobenzol.

Whatever the true etiology of jaundice, I am convinced that there is a relationship between the intensity of arseno: benzol treatment and the incidence of jaundice, as Bolam pointed out at the British Medical Association Annual Meeting in 1919, and it is on this that I have framed the course of treatment which I advocate for different types of syphilis. MacLean has suggested that empty liver cells are nore likely to take up arsenobenzol than full ones, just as the livers of starving puppies are poisoned by chloroform and those of well-fed ones escape. It may be confirmatory of this theory that one's private patients do not seen to develop jaundice on the same course of treatment as that given to clinic cases. It is possible that this is due to the fact that the liver cells of the well-to-do are better fed and less likely to take up the poison, and it may be that we go too far in the number of hours we make our patients fast before injections. On the suggestion of Professor MacLean we have for some months given our female patients at St. Thomas's Hospital a drink containing 2 ounces of glucose half an hour before each injection. It may be a coincidence, but it is worth noting that since wo adopted this practice nearly a year ago the jaundice in this department lias become negligible.

I should like now to explain the line of treatment I adopt in average cases of syphilis of different ages or infection with reference to the tables which $I$ have put up on the wall.

ROUTINE TREATMENT OF SYPHILIS CASES. A.-Primary Cases with Negative Wassermann. Alternative Arsenobenzol T'reatment.

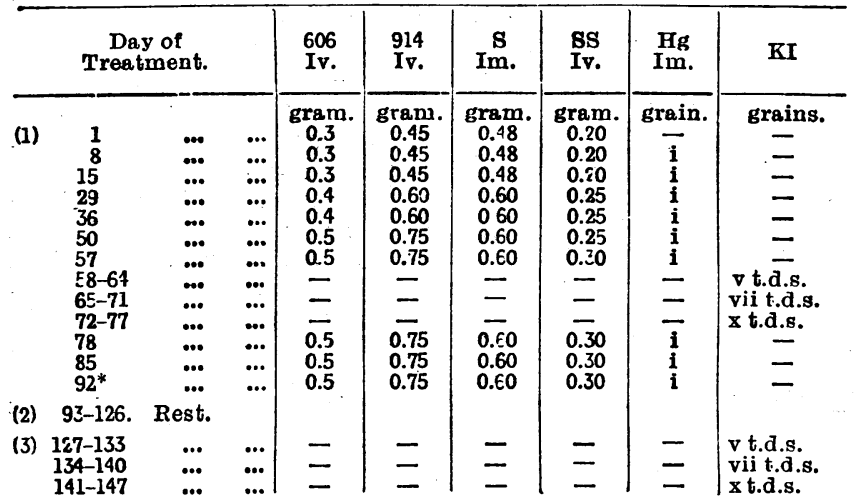

(4) Repeat treatment as from lst to $92 \mathrm{nd} d a y$.

(5) Suspend all treatment but test the blood every three months.

(6) At end of one year test blood and cerebro-spinal fluid after provocative injection.

(7) During second year test blood every six months.

(8) At end of second year test blosd and cerebro-spinal fluid after provocative injection.

\section{* Blood test on 92nd day.}

In the headings of the tables -

$606=$ Salvarsan kharsizan arsenobillon, or diersenol

$606=$ Salvarsan, kharsivan, arsenobillon, or diarsenol,
$914=$ Neo-salvarsan, neo-kharsivan, novarsenobillon, or neodiarsenol.

$\mathbf{8}=$ Sulfarsenol. $\quad$ SS $=$ Silver salvarsan.

(vo = Mercury.
B.-Primary Cases with Positive Wasserman.

\begin{tabular}{|c|c|c|c|c|c|c|c|c|c|}
\hline & \multicolumn{3}{|c|}{$\underset{\text { Triatment. }}{\text { Day of }}$} & $\begin{array}{l}606 \\
\text { Iv. }\end{array}$ & $\begin{array}{l}914 \\
\text { Iv. }\end{array}$ & $\begin{array}{l}\text { S } \\
\text { Im. }\end{array}$ & $\begin{array}{l}\text { SS } \\
\text { Iv. }\end{array}$ & $\begin{array}{l}\mathbf{H g} \\
\text { Im. }\end{array}$ & KI \\
\hline (1) & \multicolumn{3}{|c|}{$1-239^{*}$ as in "A." } & gram. & gram. & gram: & gram: & grain. & grains. \\
\hline (2) & $240-307$ & Rest. & & & . & & & & \\
\hline (3) & $\begin{array}{l}3 \cdot 8-314 \\
315-321 \\
322-329\end{array}$ & $\begin{array}{l}\ldots \\
\ldots\end{array}$ & $\begin{array}{l}\ldots \\
\cdots \\
\cdots\end{array}$ & $\bar{z}$ & $\bar{z}$ & $\bar{z}$ & $\bar{z}$ & $=$ & $\begin{array}{l}\text { v t.d.s. } \\
\text { vii t.d.s. } \\
x \text { t.d.s. }\end{array}$ \\
\hline (4) & $\begin{array}{l}3 ? 0 \\
337 \\
314 \\
358 \\
365\end{array}$ & $\begin{array}{l}\ldots . \\
\ldots \\
\ldots \\
\ldots\end{array}$ & $\begin{array}{l}\ldots . \\
\ldots . \\
\ldots \\
\ldots\end{array}$ & $\begin{array}{l}0.4 \\
0.4 \\
0.4 \\
0.5 \\
0.5\end{array}$ & $\begin{array}{l}0.60 \\
0.60 \\
0.60 \\
0.75 \\
0.75\end{array}$ & $\begin{array}{l}0.60 \\
0.60 \\
0.60 \\
0.63 \\
0.65\end{array}$ & $\begin{array}{l}0.25 \\
0.25 \\
0.25 \\
0.25 \\
0.25\end{array}$ & $\begin{array}{l}\mathbf{i} \\
\mathbf{i} \\
\mathbf{i} \\
\mathbf{i} \\
\mathbf{i}\end{array}$ & $\bar{z}$ \\
\hline
\end{tabular}

(5) Suspend treatment and continue blood tests at intervals as in "A" E-8.

* Blood test on 92nd day.

N.B.-This programme is based on the assumplion that at the end of the first ten injections the Wassermann reaction was negative. If the Wassermann reaction was positive after the tenth injection proceed as laid down for cases with secondary signs.

\section{C.-Cases with Secondary Clinical Signs.}

\begin{tabular}{|c|c|c|c|c|c|c|c|c|c|}
\hline & $\begin{array}{r}\text { Day } \\
\text { Treatn }\end{array}$ & & & $\begin{array}{l}656 \\
\text { Iv. }\end{array}$ & $\begin{array}{l}914 \\
\text { Iv. }\end{array}$ & $\underset{I m}{s}$ & $\begin{array}{l}\text { SS } \\
\text { Iv. }\end{array}$ & $\underset{\text { Im. }}{\mathrm{Hg}}$ & KI \\
\hline (1) & $-365^{*}$ as & ${ }^{\prime \prime B}$ ' & $1>4$ & gram. & gram. & gram. & Eram. & grain. & grains. \\
\hline (8) & $66-133$. & st. & & & & & & & \\
\hline & $\begin{array}{l}34-441 \\
72-448 \\
49-455\end{array}$ & ... & $\begin{array}{c}\ldots \\
\ldots .\end{array}$ & $\bar{z}$ & $\bar{z}$ & $\bar{z}$ & $\bar{z}$ & $\bar{z}$ & $\begin{array}{l}\text { v t d.s. } \\
\text { vii t.d. } \\
\text { x t.d.s. }\end{array}$ \\
\hline (4) & $\begin{array}{ll}462 & \ldots \\
469 & \ldots \\
476 & \ldots \\
490 & \ldots \\
497 & \ldots\end{array}$ & $\begin{array}{l}\ldots \\
\ldots \\
\ldots \\
\ldots\end{array}$ & $\begin{array}{l}\cdots \\
\cdots \\
\cdots \\
\cdots \\
\cdots\end{array}$ & $\begin{array}{l}0.4 \\
0.4 \\
0.4 \\
0.5 \\
0.5\end{array}$ & $\begin{array}{l}0.60 \\
0.60 \\
0.60 \\
0.75 \\
0.75\end{array}$ & $\begin{array}{l}0.63 \\
0.60 \\
0.60 \\
0.63 \\
0.63\end{array}$ & $\begin{array}{l}0.25 \\
0.25 \\
0.25 \\
0.30 \\
0.30\end{array}$ & $\begin{array}{l}\mathbf{i} \\
\mathbf{i} \\
\mathbf{i} \\
\mathbf{i} \\
\mathbf{i}\end{array}$ & $=$ \\
\hline
\end{tabular}

(5) Suspend treatment and continue observations as in "A" 5-8.

* Blood test on 92nd and 365th days.

Day of

D.-Tertiary and Latent Cases.

1- 57 ... First course of 7 injections as in " $\Delta$ " 1 .

53- 77 ... Potassium iodide.

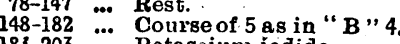

201-336 … Potassium iodide.

$337-459$.... Ditto.

370-467 … Ditto.

$568-602$ … Course of 5 as in " $B$ " 4

603-623 ... Polassium iodide.

624-749 $\cdots$... Polat.

750-784 ... Course of 5 as in "B" 4

First, as to the various terms. In the "606" class po have an array of preparations lnown under várious names, as follows: Salvarsan, arsenobenzol, arsenobillon, kluarsivan, diarsenol, arsphenamine, etc. They are all dioxydiamido arsenobenzol dihydrochloride, and require alkalization before use; they upset tho patient more, but give much better therapeutic results than "914." They are not very popular for private practice and outdoor patient work because of their inconvenience.

The "914" class, chemically dioxydiamido-arsenobenzol monomethylene sulphoxylate of soda, known as follows Neo-salvarsan, novarsenobenzol, novarsenobillon, neo-kharsivan, neo-diarsenol, neo-arsphenamine, etc. They are very convenient, because they can be given in comparatively smal balk and cause much less disturbance, and are therefore universally popular. Their disadvantage is that, when given intravenonsly, their therapeutic effect is less than that of "606." Closely allied is sulfarsenol, a preparation which has the great merit of causing little pain when given sub. cutaneously or intramuscularly. It is a preparation which I use greatly in private work, and one which has stood me well in cases with what is called an inveterate Wassermann reaction. I have always maintained that the subcutaneous injection of an arsenobenzol compound gives a better therapeutic result than if the same dose is given intravenously. The subcutaneous injertion has the further advantage that it can be given without reference to a meal. The immediate toxic effect is also less, though animal experiments sliow that the lethal dose, as well as the curative, for animals is reduced by subcutaneous injection. Silver salvarsan is a combination of sodium salvarsan with silver, and appears to be twice as 
powerful in equivalent doses. I have found it very useful in cases of tabes and other syphilitic diseases of the central nervous system.

Mercury I prefer to give in the form of mercurial cream or as salicylate by intramuscular injection, because it acts better than when given by the mouth, and injection is more convenient than inunction.

You will see from the table that I have divided my cases into different types:

Primary cases with negative Wassermann reaction. Primary cases with positive Wassermanu reaction.

Secondary cases.

Later or old-standing cases.

Nerve cases.

The treatment prescribed increases with the age of the infection. The scheme on which the unit course is distributed is very similar in all but the nerve cases. The start is with three moderate doses; that is to avoid encephalitis, of which I have personally seen only two comparatively mild cases. There are various gaps after the third, fifth, and seventl injections. These are in order to give susceptible cases a cliance of showing sigus of intolerance before too many injections have been given. I may say that in my clinic at St. 'Thomas's Hospital the skin and mucous membrane of all patients are examined and the urine tested before each injec. tion, and to that I attribute our comparative immunity from serious toxic effects. 'The same routine was adopted, with similarly happy results, in my hospital in France and at Rochester Row as soon as it was realized how easy it is to overlook such signs of intolerance as slight erythemata and to pile fuel on fire by giving more injections.

At various points a ccurse of iodide is given; that is in the belief that iodide assists the resolution of the process. I conceive the unit syphilitic lesion as a colony of spironemes surrounded by a wall of more or less fibrosed tissue, and so protected from agents circulating in the blood. I regard the iodide as an agent which will stimulate the tissues to break down that wall and let in the antisyphilitic remedy to the spironemes within.

The minimum treatment proceeds fa beyond the stage when the Wassermann reaction has become negative. Many workers consider that, when the Wassermann reaction has been rendered negative, treatment may be suspended, or at least mercury can be relied upon to complete the cure. This implies a belief that, when the Wassermann reaction has been rendered negative, the germ of syphilis lias been almost eradicated. I should like to contest this view, because if it is not correct thousands of syphilitics are to-day being treated insufficiently and will remain syphilitic to the end of their lives. It is useless to say that, if the initial treatment is insufficient, the error will be corrected when the patient relapses. All of us know quite well that a large proportion of insufficiently treated cases do not relapse with clinical signs but only serologically. We know also that, so long as no outward signs appear, very many patients do not trouble to ctrme for blood tests, so that the serological relapse goes undetected for months, if it is ever discovered. I would remind you that the skin and mucous membranes are not the only parts of the body in which the germ of syphilis flourishes and that a patient may be a public danger as well as a candidate for future dependence on the charity of his friends and relations, though he may have shown no outward signs of syphilis for years.

With regard to the negative Wassermann reaction as a guide to cure, nobody knows how much spirochaetal activity is required to produce a positive Wassermann reaction. We know that it varies in different patients, and there are some who may show such gross outward signs of syphilis as a papular eruption, mucous patches, and condylomata, and yet give a negative reaction, and we know also that very many patients who have been treated only until the Wassermann reaction has become negative subsequently relapse, proving that the germ of syphilis was by no means eradicated by the

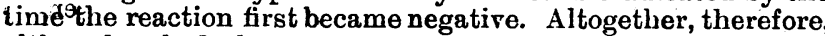
although nobody knows how much detilry is going on behind the veil of a negative reaction, everybody knows that it may be considerable, and I contend that we are not justified in assuming either that treatment may be suspended when the Wassermann reaction first becomes negative, or that it may safely be continued with mercury only to complete two years. I hâ given reasons for showing that mercury given for two years, administered in the only forms which are practicable for the inultitude, leaves a high proportion of cases uncured, and I hold very strongly that every remedy at our disposal should be employed in the continuation treatment. The amount and length of the continuation treatment should, in my judgement, be that which observation in the past has shown to result in no relapses after pro'onged suspension of treatment.

I do not believe in being guided by the progress of the patient except, of course, as regards signs of intolerance of treatment. That policy means giving a certain amount of treatment, which in some cases has apparently resulted in cure bit in others has been followed by relapse, and then watching to see how it works in this particular case. If the patient docs relapse he is in much worse case, and often by this time he has passed the disease on to some other person. It is not in this way that we shall eradicate syphilis. Most of the cases of syphilis we are treating to-day are under our care becauso of the introduction of a public health measure which aims to stop the spread of this disease by rendering the greatest possible number of persons permanently non-infective. it is not $1 \mathrm{~m}$ rely the hiding away of a sore, a rash, or an ulcerated throat, or even the rendering of the patient temporarily non-infective, but the stopping of any further chance of that patient passing on the disease to others. If we merely introduce an interval of a few months of non-infectivity we are not fulfilling the public health ideal; in fact, the money spent on the treatment of the patient is largely wasted Lastly, in favour of my plea for a treatment. which does not stop until there are very strong reasons for believing that the disease has been eradicated, I would suggest to you that it is nothing less than this which would satisfy any of us if we were so unfortunate as to contract syphilis.

The plan I have laid down for later cases consists of a number of short courses. Many hold that it is useless treating an old-standing case with a positive W'assermann reaction beyond the stage when the symptoms have gone. They say that the Wassermann reaction will never be changed however much treatment is given. This is not correct; if the treatment is prolonged the reaction often does become negative, and the gradual change can be watched if the strength of the reaction is titrated out. Some ask, What, after all, does a positive Wassermann reaction matter? Many hale and hearty men, they say, have a positive Wassermann reaction and are none the worse for it. Other workers hold that a positive Wassermann reaction in late cases signifies only that the patient has at some time suffered from syphilis, and that it does not spell present activity of Spironema pallidum. If so, I would ask why the reaction diminishes in strength and may die out under prolonged treatment, and the patient's general health improves in the process. I do not agree that a positive Wassermann reaction is a trifling sign. If the apparently hale and hearty person with a positive Wassermann reaction is examined critically $h \theta$ is often found not to be so hale and hearty as he appears to a casual observer. He is of the type who drops down dead or begins some day to talk nonsense and act irresponsibly, and I agree with Stokes, who says that those who regard a positive Wassermann reaction as indicating nothing more than a high resistance should at least submit their cases of the kind to expert clinical examination before continuing to hold that belief. He found that such an expert examination disclosed a high percentage of disease, particularly cardiac and nervous, and $I$ would again remind you that the skin and visible mucous membranes are not the only parts of the body on which the germ of syphilis acts. It is my experience that very many patients with a strongly positive reaction say on commencing treatment that they feel all right in themselves, but the same patients remark at a later date that they feel fitter now than they have done for years.

For nerve cases the course outlined shows a frequent repeti. tion of small doses, preferably of silver salvarsan, which seems to act particularly well in getting rid of the lightning pains of tabes. Although the course commences very mildly you will see that the total amount administered is not small, and it is wise not to allow too long an interval between courses.

If general paresis be excepted I think the outlook for nerve cases is generally good, provided that the treatment is insti. tuted fairly early, and I have had excellent results in tabes from long-continued arsenobenzol, mereurial, and iodide treat. ment. General paresis is a different matter, and I think that most workers are pessimistic regarding the outlook in these cases. Since the present prognosis is so hopeless, and any measure which offers a glimmer of hope is justifiable in general paresis, I may perhaps be pardoned for relating a case of my own in which I think that treatment has definitely 
E.-Nerve Cases.

Arsenobillon Argentum or Silver Salvarsan.

\begin{tabular}{|c|c|c|c|c|c|}
\hline & & & $\underset{\text { Day of }}{\text { Treatment. }}$ & $\begin{array}{l}\text { Gram } \\
\text { Intravenously. }\end{array}$ & $\underset{\text { Grains. }}{\text { III }}$ \\
\hline lst course & $\cdots$ & $\ldots$ & $\begin{array}{r}1 \\
4 \\
8 \\
11 \\
18 \\
22 \\
25 \\
27 \\
32 \\
36 \\
39 \\
43 \\
44-50 \\
51-57 \\
58.64\end{array}$ & $\begin{array}{l}0.15 \\
0.15 \\
0.15 \\
0.5 \\
0.20 \\
0.20 \\
0.20 \\
0.20 \\
0.25 \\
0.25 \\
0.25 \\
0.25 \\
= \\
=\end{array}$ & $\begin{array}{c}\bar{z} \\
\bar{z} \\
\bar{z} \\
\bar{z} \\
\bar{z} \\
\bar{z} \\
\text { v t.d.s. } \\
\text { x t.d.s. } \\
\text { xv t.d.s. }\end{array}$ \\
\hline 2nd course & $\cdots$ & ... & $\begin{array}{rl}85-148 & R \\
149-203 & R\end{array}$ & teat 1-67. & \\
\hline 3rd course & $\cdots$ & $\cdots$ & $\begin{array}{ll}2<4-: 67 & R \\
258-250 & R\end{array}$ & teat 1-64. & \\
\hline 4 th course & $\cdots$ & $\cdots$ & $\begin{array}{ll}35 !-413 & R \\
417-511 & R\end{array}$ & t. $1-61$. & \\
\hline 5th course & $\ldots$ & $\ldots$ & $512-575 ?$ & peat $1-64$. & \\
\hline
\end{tabular}

influenced the course for the better and has certainly had a profound effect on the serum and fluid reactions. It shows also the extraordinary amount of arsenobenzol which some patients may receive without apparent ill effect.

This patient came under my care in June, 1921. He had then been in a private asylum for eight months, with typical signs of general paresis. The history of syphilis dated to about thirty years previously. He was grandiose, had slight tremor of tongue and lips, Argyli Robertson pupil, and slight Rombergism. The bloodserum reaction and the cerebro-spinal fluid reactions were strongly positive. The cerebro-spinal fluid contained 250 cells per cubic millimetre, and the globulin content was marked. He had recently received seven injectious of "914," and this treatment had then been abandoned as no improvement had resulted. I was asked to do anything which offered the slightest hope of cure, regardless of risk. I stipulated that treatment should not be abandoned unless no improvement had followed at least twenty arsenobenzol injec. tions. I decided to combine injections with spinal drainage. 'I'he treatment and progress were as follows:

From July 3rd to July 31st, 1921, I gave 1.5 gram silver salvarsan in seven intravenous, and 0.6 gram sulfarsenol in two intramuscular injections, and drew off $140 \mathrm{c} . \mathrm{cm}$. of cerebro-spinal fluid by three punctures. The patient then refused all further treatment, and showed generally no improvement; if anything he seemed slightly worse than when treatment commenced. During August and September he improved sufficiently to cause his wife to press for his removal to his home, where the further treatment has been carried out. Treatment was resumed on October lst, 1921, when he was fairly quiet, though delusional on certain matters, such as religion, and grandiose on mouey matters. The cerebro-spinal fluid gave a strongly positive Wassermann reaction, but the cells numbered onfy 6 per cubic millimetre.

From October lst to November 26th, 1921, I gave him 3.2 grams of silver salvar'san in seven injections, ranging from 0.3 to 0.6 gram, and drew off $275 \mathrm{c.cm}$. cerebro-spinal fluid by seven punctures. Under this treatment he improved very considerably, shedding much of the general paretic mental outlook and behaviour. The Wassermann reaction of his spinal fluid became weaker, giving a reaction only in a dilution of 1 in 2.5 and higher concentrations, and the cells numbered 2 per cubic millimetre. Lange's gold test, however, gave a strongly marked raretic curve. Treatment was however, gave a strongly marked raretic curve. Treatment was
suspended from November $26 \mathrm{th}, 1921$, to February 18th, 1922, and it was interesting to observe how he relapsed gradually during the last month of this interval, becomiug more and more general paretic, until at last he was quite as bad as on his first return home. I decided to push the treatment far more intensively, and from February 18th to April 4th, 1922, I gave 8.55 grams silver salvarsan in ten injections, ranging from 0.6 to 1.25 gram, and irew off $220 \mathrm{c.cm}$. spinal tluid by six punctures. The injections were well tolerated, mainly, I think, because they were given in 7 per cent. glucose, and 2 oz. glucose were administered by the mouth one hour before each injection.

The clinical improvement under this treatment has been most marked, and he is now more nearly normal than he has been since he was certified as insane about a year ago. He can criticize a book as intelligently as before his illness commenced and write a sensible letter with no omissions. His balance, formerly very unsteady, is now firm and he walked fifteen miles a few weeks ago. His conversation is generally rational and his memory good, but he is still rather delusional on religion and Christian Science. The improve ment in his house manners is particularly marked. He is normally very considerate for others, but in the relapse preceding the las course of treatment he became definitely coarser in his genera behaviour; after the treatment was resumed his normal refinement of behaviour gradually returned. His fluid now contains 1.3 cells per cubic millimetre, gives only a partial Wassermann reaction with one whole volume, and the gold-sol reaction is definitely weaker. The blood-serum reaction is now negative.

[Note on Correction, June 11th, 1922.-This patient is now normal in behaviour minder all conditions, except in regard to the healing porvers of Christian Science, in which he is definitely more optimistic than the average adherent of that faith.]

Of course, remissions occur in general paralysis of the insane without treatment, as everyone knows, but in this case it is difficult to attribute the second improvement, dating from the commencement of the last course and proceeding steadily to the end of it, to any other cause than the huge doses of silver salvarsan administered. 'The case is incomplete, but has proceeded far enough to show that colossal doses of silver salvarsan do affect adversely the deeply buried spironemes in general paresis, and that is my excuse for relating it at such a comparatively early stage.

\section{THE PLACE OF OPHTHALMOLOGY IN THE UNDER- GRADUA'TE MEDICAL CURRICULUM.;} $\mathbf{B Y}$

\section{W. GORDON M. BYERS, M.D., MONTREAL.}

"In education, most time is to be bestowed on that which is of the greatest consequence in the ordinary course and occurrences of the life the young man is designed for."

LOCKE.

WHAT part of ophthalmology shall be taught in the undér. graduate medical course? How much time shall be devoted to the subject? 'These are important questions; for in seeking to determine the place of ophthalmology in the undergraduate medical curriculum one is faced at the outset, not only with the problem of what to do with the specialties in general, but also with the whole problem of undergraduate medical teaching.

A great deal oì time and thought has been advantageously devoted in recent years to the subject of post-graduate ophthalmic studies, but apparently very little by comparison las been given to undergraduate work. The reason probably is that the post.graduate studies present a circumscribed field that falls largely to teachers in the specialties for solution, while undergraduate studies in any one subject are but a single factor in a much larger problem, in which workers in all the branches of medicine are interested.

It seems a duty for oplithalmologists to take part in the widespread deliberations that are shaping the policies of all medical schools; especially so as some of the proposals that have been made in regard to the disposition of special studies are obviously founded upon a misconception of values and of the primary purpose of undergraduate medical education.

Before beginning the study of the problem we must set clearly before ourselves exactly what we wish to accomplish in undergraduate teaching. We still touch hands with those for whom it was possible in their college years to gain a fairly comprehensive grasp of the whole range of the medical knowledge of the time; but the phenomenal development of medicine during the last few decades has made this less and less attainable. Students are now forced to confine themselves to phases of the old major subjects, to subjects of recent development, and even, again, to ramifications of them. We have, in a word, wituessed an extraordinary development of specialization. The problem of undergraduate work is to-day, therefore, much more complex. Men aim not at one goal, but aspire to varied fields of endeavour.

As a starting point we must classify students in accordance with what they have in view. This is not a difficult matter, for quite simply our students fall into three groups: Those who are destined to be general practitioner's; those who will be clinical specialists; and those who will specialize in research, teaching, and public health.

The specific business of the general practitioner is to treat sick individuals-in other words, to grapple with distinctive medical problems. Some of these problems are of little or no moment; others are of vital importance; and many of them are clearly beyond the scope of the general practitioner. It is obvious that in order to see clearly what are the require. ments of the general practitioner in the way of instruction and training, we must set forth his problems and make some kind of ciassification in accordance with their relative volues. Clearly, the only standard of classification one can adopt

* Read before the American Ophthalmological Society, Washington. Nay 2nd, 1922. 